Original Research Paper

\title{
Gears-Part II
}

\author{
${ }^{1}$ Relly Victoria V. Petrescu, ${ }^{2}$ Raffaella Aversa, \\ ${ }^{3}$ Bilal Akash, ${ }^{4}$ Ronald B. Bucinell, ${ }^{5}$ Juan M. Corchado, \\ ${ }^{2}$ Antonio Apicella and ${ }^{1}$ Florian Ion T. Petrescu \\ ${ }^{I}$ ARoTMM-IFToMM, Bucharest Polytechnic University, Bucharest, (CE), Romania \\ ${ }^{2}$ Advanced Material Lab, Department of Architecture and Industrial Design, \\ Second University of Naples, 81031 Aversa (CE), Italy \\ ${ }^{3}$ Dean of School of Graduate Studies and Research, American University of Ras Al Khaimah, UAE \\ ${ }^{4}$ Union College, USA \\ ${ }^{5}$ University of Salamanca, Spain
}

Article history

Received: 31-12-2016

Revised: 07-01-2017

Accepted: 09-05-2017

Corresponding Author:

Florian Ion T. Petrescu

ARoTMM-IFToMM,

Bucharest Polytechnic

University, Bucharest, (CE),

Romania

Email: scipub02@gmail.com

\begin{abstract}
The paper presents an original method for the determination of the yield of the gearbox, gears forces, gearbox and power. It analyzes the influence of certain parameters which affects the efficiency of the gearbox. Also an original method for the determination of the yield of the drive shafts oriented on the basis of the ratio of contact is presented the brief. The relations submitted, can be dynamic synthesis of the drive shafts oriented, in order to enhance the effectiveness of the mechanisms of mesh.
\end{abstract}

Keywords: Kinematics, Forces, Velocities, Powers, Gears, Efficiency, Geometry, Synthesis, Yield

\section{Introduction}

\section{Mechanical Transmissions}

A transmission is a mechanical device for transmitting movement from one part to another.

This element of the energy chain has for function the adaptation of the torque and of the speed between the driving member and the driven member.

The transmission of motion is one of the most common functions of the elements of general mechanics, that is to say, mechanical devices intended to replace the hand of man.

According to the mechanisms, the transmission is dimensioned according to considerations concerning: The position of a part of the mechanism; the desired movement; the force, or the couple sought; the power.

\section{Modes and Transmission Components}

\section{Solid Contact Transmission}

By pressure:

- In the case of a rotation

- Pulling by rope, rope, strap or tie rods

- By Obstacles
Transmission by chain, synchronous belt, rack only in case of avoidance of slippage:

- Gears

By adhesion:

- Wheel

- Smooth belt

- Clutch

\section{Fluid Transmission}

Pneumatic: Compressed air or any other gas,

Hydraulic system: Water, oil or any other liquid such as brake fluid.

\section{Contactless Transmission}

Using electromagnetism: Magnet, electromagnet

\section{Transmission with Additional Functions}

In some cases, the environment requires the use of specific components within the transmission: Elastic coupling when absorbing shocks 
Cardan joint, Oldham seal to transmit the movement between two trees whose alignment is not always guaranteed (Mirsayar et al., 2017).

\section{Performance of a Transmission}

\section{Power Transmission Efficiency}

In the case of power transmission, the objective is generally to limit losses.

The yield is then defined (I):

$\left\{\begin{array}{l}\eta=\frac{\text { The work output }}{\text { The work input }}=\frac{L_{o}}{L_{i}} \\ =\frac{\text { The power output }}{\text { The power input }}=\frac{P_{o}}{P_{i}}\end{array}\right.$

A conventional gear has a yield greater than $95 \%$ (0.95).

\section{Ratio of a Transmission of Rotational Motion}

The transmission ratio is defined as the ratio of the velocities of the output motion to the input movement.

Most of the time, it is a proportional law that does not depend on the position of the mechanism.

It is expressed most often as a relationship on speed, but the report on travel is the same (II):

$$
i_{i o}=R=\frac{\text { The output rotation velocity }}{\text { The input rotation velocity }}=\frac{\omega_{o}}{\omega_{i}}
$$

A gear is a system composed of two mechanical parts provided with teeth or threads which interpenetrate in such a way that one of these parts can drive the other in rotation or in translation.

These parts may be toothed wheels, racks or worms. The most frequent gear is composed of two toothed wheels external to each other, the smallest of which is called a pinion.

When the contact is internal, we no longer speak of a wheel but of a toothed crown.

There are many types of gears, which can be classified according to various criteria:

- Form of the toothing (we speak of profile)

- Relative position of the axes: Parallel, concurrent or arbitraryș

- Inclination of the teeth (straight, helical, herringbone..${ }^{\circ}$ )

When a mechanism has several gears, it is called a gear train (Mirsayar et al., 2017).

Two situations must be distinguished:
The simple trains are those for which, in a given reference space, all the elements rotate about their own axis of revolution; these are the simplest to calculate.

The planetary trains or epicyclic trains are those for which, in a given reference space, certain elements rotate about axes which are not their axes of revolution.

They often pose serious problems of calculation to the students and even to some of their professors.

Other related mechanisms have similar properties to rigid toothed wheels.

These are, for example, the deformable toothed bells of the Harmonic Drive speed reducers, the toothed (and not serrated) transmission belts, still more or less incorrectly known as "synchronous belts", transmission chains, certain indexing mechanisms, etc. In Fig. 1 one can see the constructive photo of harmonic drive and in Fig. 2 its diagram.

All these mechanical elements provide a transmission of movement and force by meshing with teeth and hence by an obstacle.

In Fig. 3 may be seen several mechanisms rotary cam and cam followers.

In Fig. 4 can be observed a mechanism with an universal joint and the other one with two universal joints and the mini shaft. In Fig. 5 one can see a Geneva drive mechanism (Mechanism with cross of Malta), first one with one beginning and second one with two beginnings. In Fig. 6 one can see a differential mechanism. In Fig. 7 one may see two mechanical transmissions of space with bars. Spatial mechanical transmission, ball, the cylinders and the pistons, used to pumps and motors rotating will be seen on the Fig. 8 .

Figure 9 shows some mechanical reduction in speed and Fig. 10 some manual gearboxes used in road vehicles. In Fig. 11 one can see a worm gear and in Fig. 12 some ratchets.

Figure 13 shows us a few planetary mechanisms used and in the construction of the automatic transmission (Fig. 14).

Gears are present today in all the fields of activity. They offer the advantage of working with very high efficiency (Maros, 1958; Stoica, 1977).

Irrespective of their size, gears must be compiled taking into account the conditions carefully.

The work from the front is trying to present the main conditions which must be met in order to correct the synthesis of a gear (Petrescu and Petrescu, 2002; 2003; Petrescu et al., 2007; Petrescu, 2013).

The climax of the mechanisms using the toothed rollers must be sought in the Ancient Egypt, with at least a thousand years before Christ.

Drive wheel, "stimulated" for irrigation of crops and implements for the processing of cotton (Lei et al., 2011; Lin et al., 2011) were used here for the first time. 
In the year 230 B.C., in the city of Alexandria, Egypt, have been used for wheels with more usually took with the steering rack.

Also, instruments which have been constructed and used from the most ancient times, above all for lifting heavy anchors of vessels and the wind remove arms used on the fields of battle.

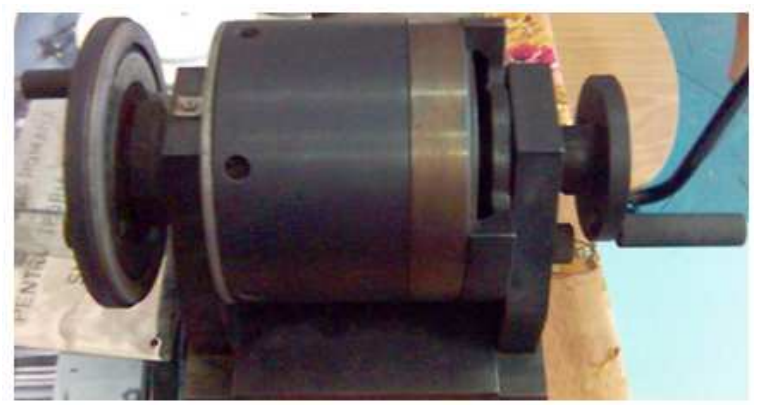

Fig. 1. Constructive photo of a harmonic drive

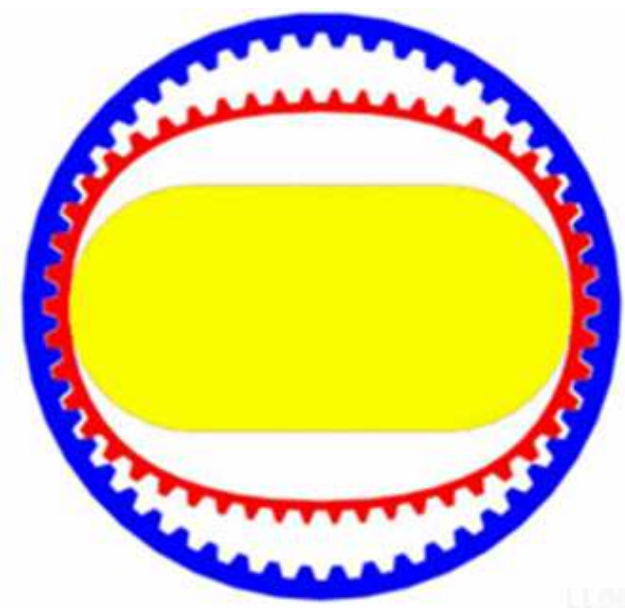

Fig. 2. Diagram of a harmonic drive

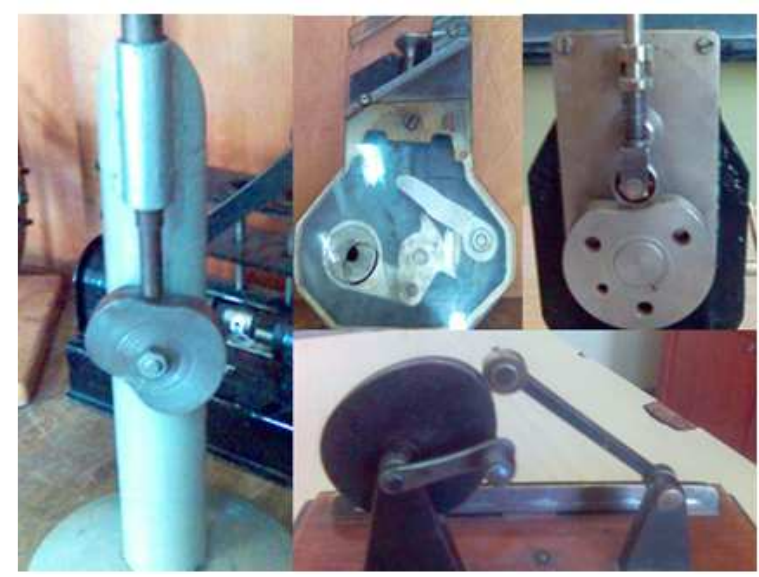

Fig. 3. Mechanisms with rotary cam and follower
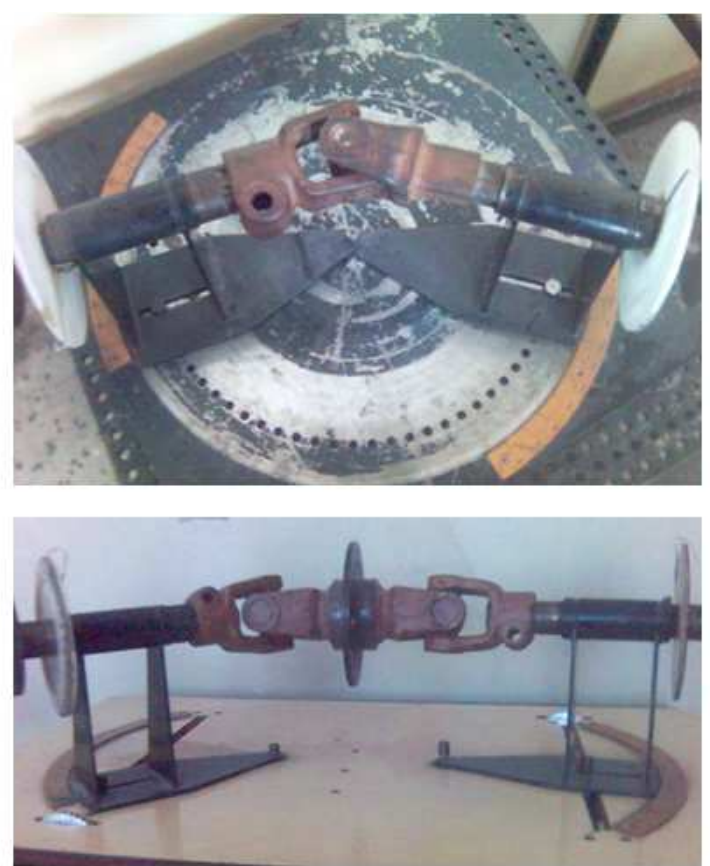

Fig. 4. A mechanism with an universal joint and the other one with two universal joints and the mini shaft
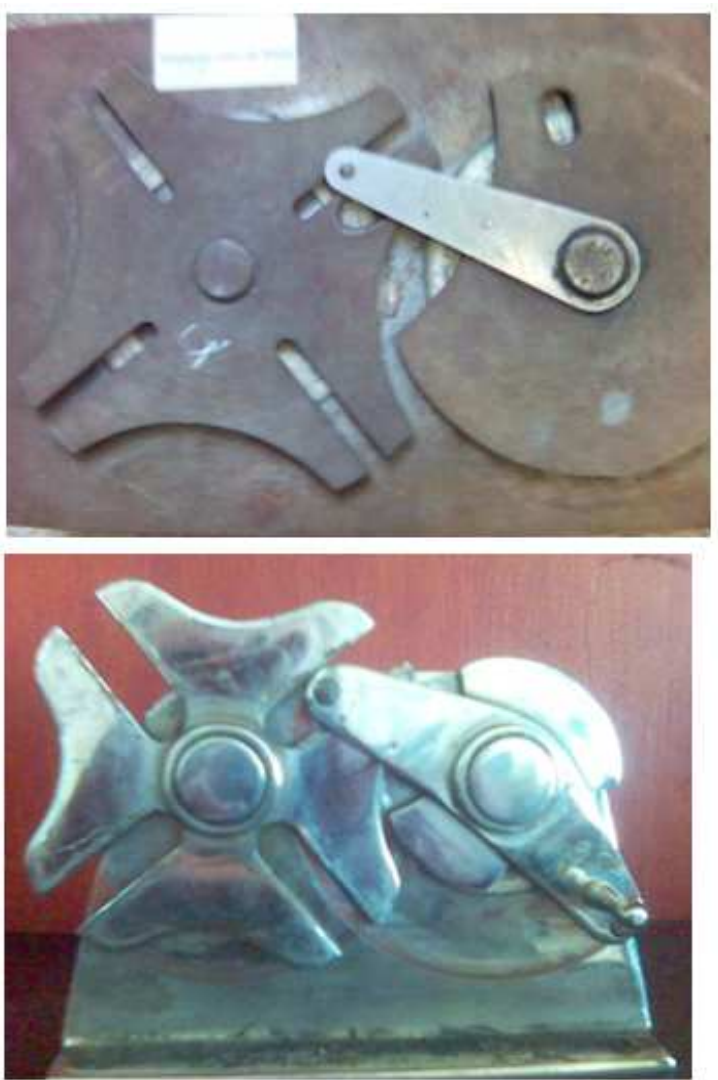

Fig. 5. A Geneva drive mechanism (Mechanism with cross of Malta), first one with one beginning and second one with two beginnings 


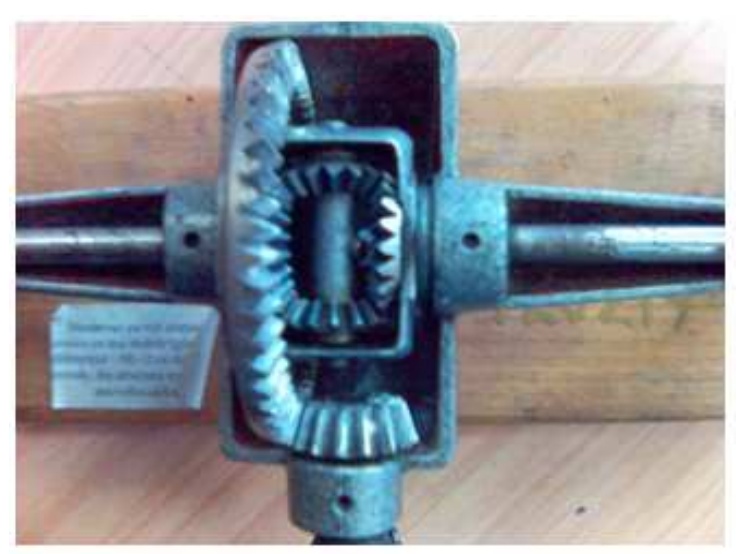

Fig. 6. A differential mechanism

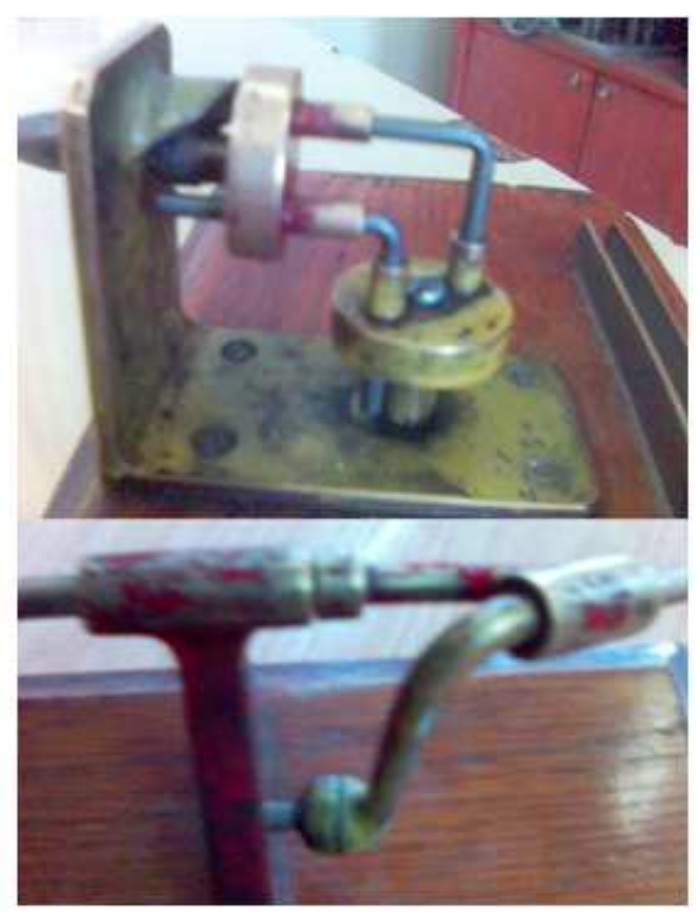

Fig. 7. Two mechanical transmissions of space with bars

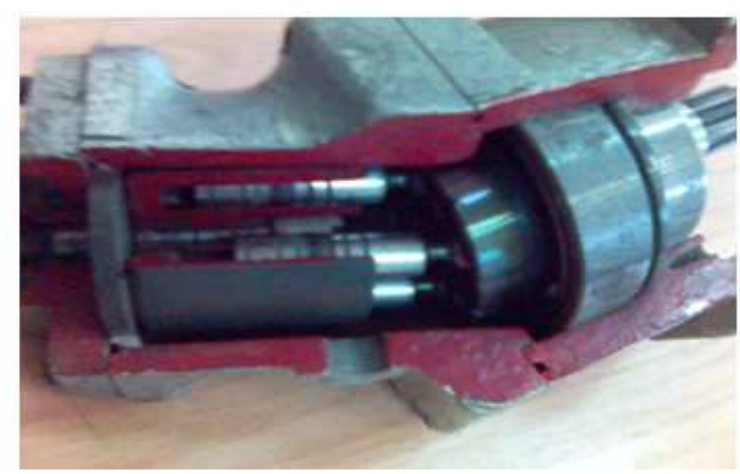

Fig. 8. Spatial mechanical transmission, ball, the cylinders and the pistons, used to pumps and motors rotating

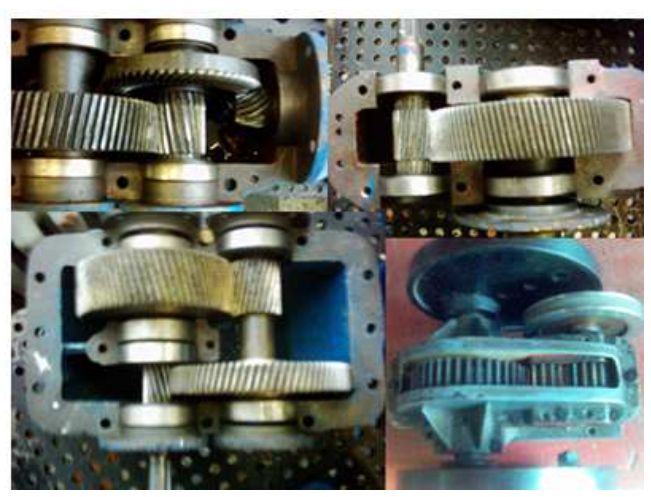

Fig. 9. Some mechanical reduction in speed

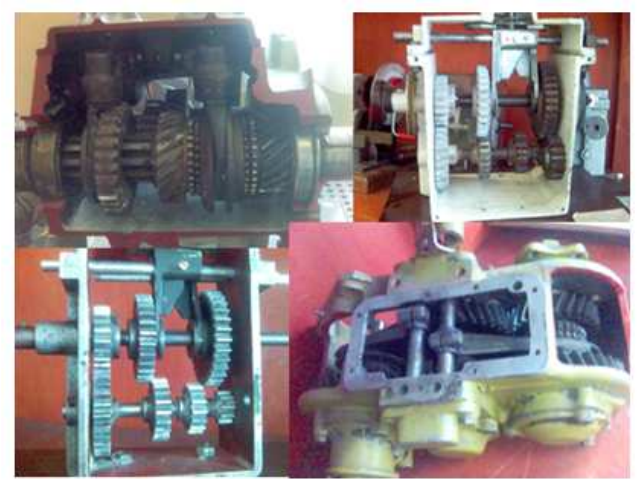

Fig. 10. Some manual gearboxes used in road vehicles

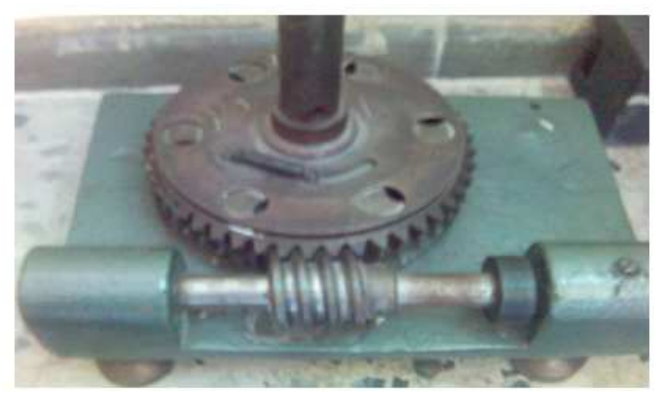

Fig. 11. Worm gear

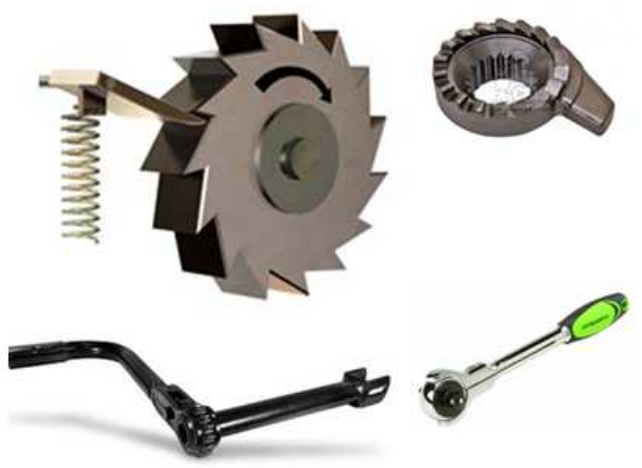

Fig. 12. Ratchets 


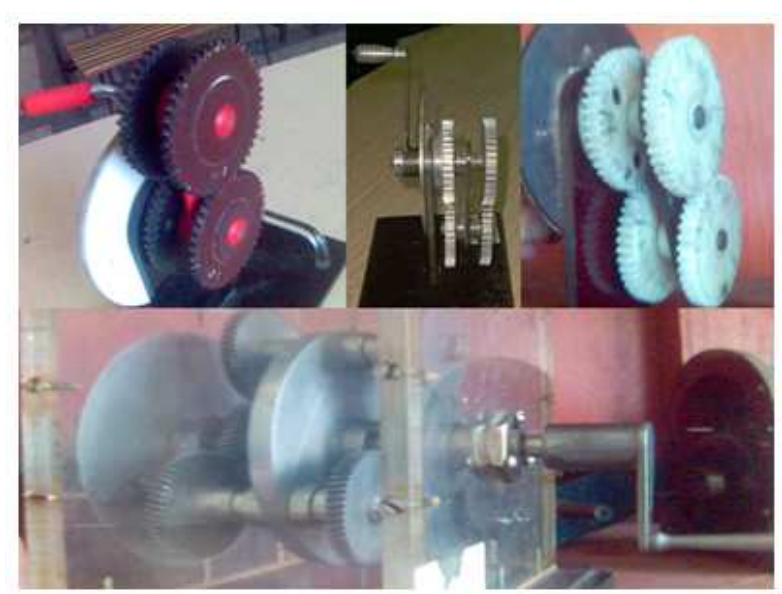

Fig. 13. Planetary mechanisms

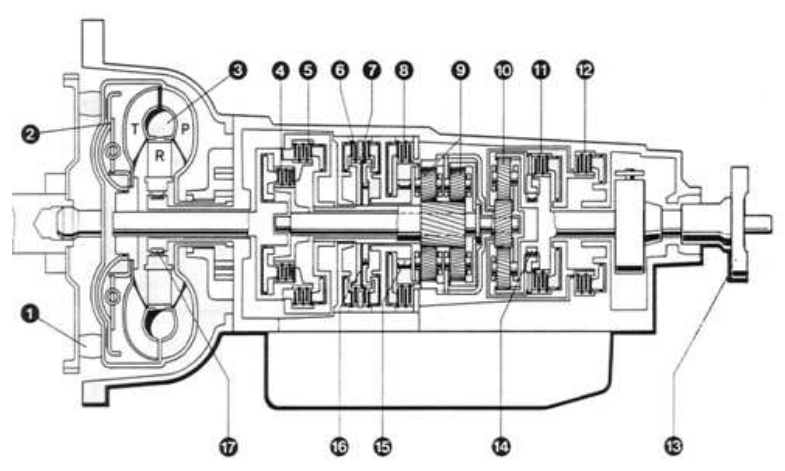

Fig. 14. An automatic transmission

Subsequently, have been introduced in the vehicles with wind and water, to reduce or increase the pump which emanates from the die by wind or water.

Antikythera is the name given to a computing device by measuring the astronomically approximately 32 up to $16 \times 10 \mathrm{~cm}$, which was discovered in 1900 in a vessel which sank just off the coast of Antikythera, an island between Crete and mainland Greece.

Several types of types of sampling point around the 80 unquestioned I for shipwreck; the appliance, manufactured from gears of bronze mounted in a case of wood, has been crushed in an accident and parts of the girls were lost, the rest being then covered with a kelp difficult to coralline deposit at the same time as and metal corroded on a core in a thin layer covered with flooring metal salts holding at the same time a large part of the former form during the almost 2,000 years, withdrawn from aside immerse.

Modern adventure began with the toothed wheel stimulated by Leonardo da Vinci, in the 15th century. He founded the moving parts and dynamic, specifying inter alia, the principle of independent movements super positions. Benz has had the engine with chain drive gearbox with the sprocket and the gearbox (proprietary product in 1882), (Matos and Marinho, 2011; Nogueira and Real 2011; Oliveira and Lima, 2003), but the first patent from the gearbox (drawings of the first transmissions of the gearbox patented) and the wheels of the net with the chain have been completed in 1870 by British Starley and Hillman (Rey, 2013).

In 1912, in Cleveland (USA), the production of industrial wheels and specialized fishing gear drums (worm, conical flask with teeth righteous, tilt or curved) has started (Mirsayar et al., 2017).

Today, the gears are present all over the world, mechanical, such as the automobile industry, electronics and equipment for electro-technical, energy industry, etc (Matos and Marinho, 2011; Nogueira and Real, 2011; Oliveira and Lima, 2003).

In today's world, more than $80-90 \%$ of the mechanical drives used are the drive shafts, the camshaft and gears. For this reason, it is necessary to be investigated and to improve constantly in these mechanisms, widely used.

\section{Determining the Gear Efficiency as a Function of Contact Ratio}

The calculation of the efficiency of a drive shafts with tools for a reduction, taking into account the fact that, at a given moment, there are several pairs of teeth in contact and not just one (Maros, 1958).

Therefore, the initial model includes four pairs of teeth in contact (4) at the same time (Pelecudi et al., 1985; Petrescu and Petrescu, 2002; 2003; Petrescu et al., 2007; Petrescu, 2013).

The first teeth mesh in the contact has the contact point I, defined by $r_{i 1}$ with the rays and the angle of $\alpha_{i 1}$ pressure (Mirsayar et al., 2017).

The forces which operate at this time are: Engine force $\mathrm{F}_{\mathrm{mi}}$, perpendicular to the position of the vector $r_{i 1}$ to $i$ and force transmitted from the wheel 1 to 2 wheels through the point $i, F_{t i}$ parallel with the way of action and with steering wheel 1 to 2 wheels.

The force transmitted is practically the projection of the force of the engine on the path of the action. defined speeds are similar to the forces (having regard to the original cinematic, or precise cinematic adopted).

The same parameters are defined for the other points of contact with the three $-j, k$ and $l$ (Fig. 15).

The quantities of interest are: $r_{b 1}$-the base radius of the drive wheel $1 ; \omega_{1}$-the circular velocity of wheel 1 ; $z_{1}$-the number of teeth of the wheel $1 ; \alpha$-the pressure angle, so that $\alpha_{1}$ is the pressure angle for the wheel 1 and $\alpha_{0}$ is the normal pressure angle on the pitch circle. 


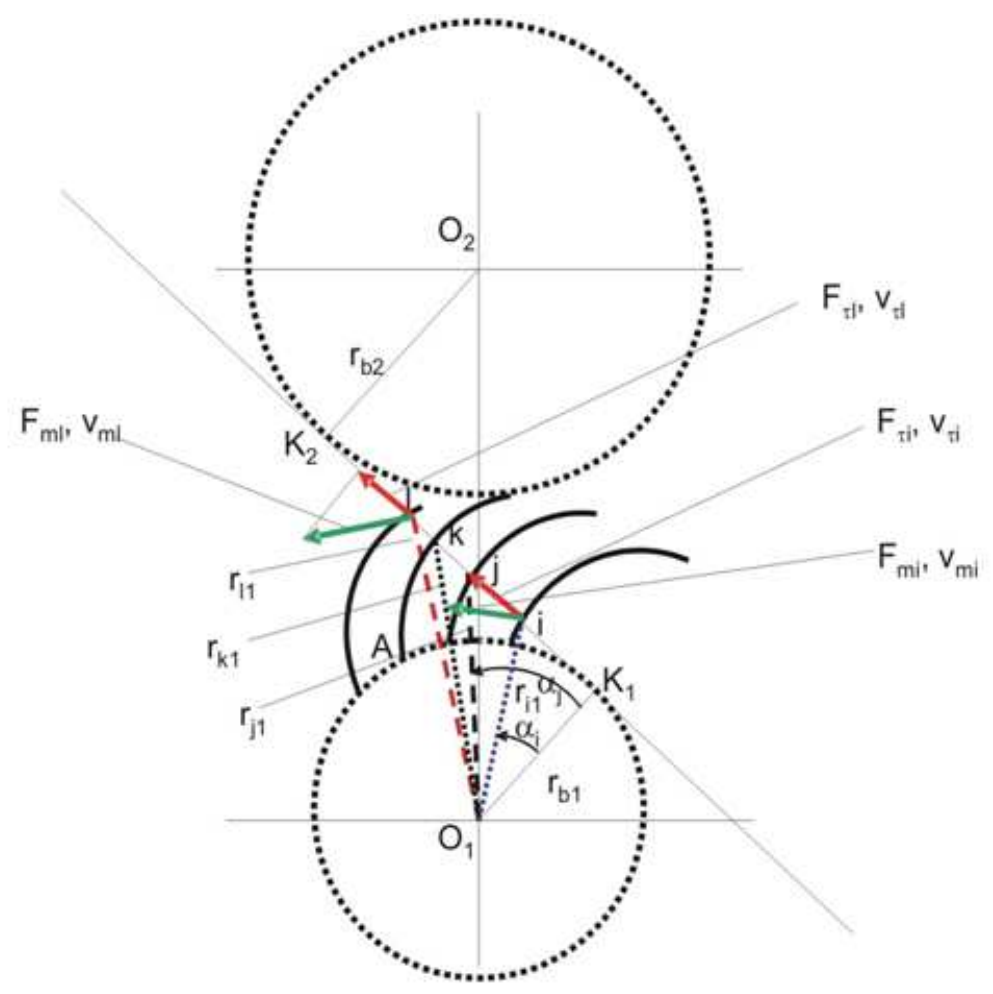

Fig. 15. Four pairs of teeth in contact concomitantly

As a starting point, one write the relations between the velocities (Petrescu and Petrescu, 2002; 2003; Petrescu et al., 2007; Petrescu, 2013):

$$
\left\{\begin{array}{l}
v_{\tau i}=v_{m i} \cdot \cos \alpha_{i}=r_{i} \cdot \omega_{1} \cdot \cos \alpha_{i}=r_{b 1} \cdot \omega_{1} \\
v_{\tau j}=v_{m j} \cdot \cos \alpha_{j}=r_{j} \cdot \omega_{1} \cdot \cos \alpha_{j}=r_{b 1} \cdot \omega_{1} \\
v_{\tau k}=v_{m k} \cdot \cos \alpha_{k}=r_{k} \cdot \omega_{1} \cdot \cos \alpha_{k}=r_{b 1} \cdot \omega_{1} \\
v_{\tau l}=v_{m l} \cdot \cos \alpha_{l}=r_{l} \cdot \omega_{1} \cdot \cos \alpha_{l}=r_{b 1} \cdot \omega_{1}
\end{array}\right.
$$

From Equation 1, one obtains the equality of the tangential velocities (Equation 2) and, furthermore, the motor velocities are explicitly obtained (Equation 3):

$v_{\tau i}=v_{\tau j}=v_{\tau k}=v_{\tau l}=r_{b 1} \cdot \omega_{1}$

$v_{m i}=\frac{r_{b 1} \cdot \omega_{1}}{\cos \alpha_{i}} ; v_{m j}=\frac{r_{b 1} \cdot \omega_{1}}{\cos \alpha_{j}} ; v_{m k}=\frac{r_{b 1} \cdot \omega_{1}}{\cos \alpha_{k}} ; v_{m l}=\frac{r_{b 1} \cdot \omega_{1}}{\cos \alpha_{l}}$

The forces transmitted concomitantly at the four points must be equal:

$$
F_{\tau i}=F_{\tau j}=F_{\tau k}=F_{\tau l}=F_{\tau}
$$

The motor forces are given as:

$$
F_{m i}=\frac{F_{\tau}}{\cos \alpha_{i}} ; F_{m j}=\frac{F_{\tau}}{\cos \alpha_{j}} ; F_{m k}=\frac{F_{\tau}}{\cos \alpha_{k}} ; F_{m l}=\frac{F_{\tau}}{\cos \alpha_{l}}
$$

The momentary efficiency can be written in the following form:

$$
\begin{aligned}
& \eta_{i}=\frac{P_{u}}{P_{c}}=\frac{P_{\tau}}{P_{m}}=\frac{F_{\tau i} \cdot v_{\tau i}+F_{\tau j} \cdot v_{\tau j}+F_{\tau k} \cdot v_{\tau k}+F_{\tau l} \cdot v_{\tau l}}{F_{m i} \cdot v_{m i}+F_{m j} \cdot v_{m j}+F_{m k} \cdot v_{m k}+F_{m l} \cdot v_{m l}} \\
& =\frac{4 \cdot F_{\tau} \cdot r_{b 1} \cdot \omega_{1}}{\frac{F_{\tau} \cdot r_{b 1} \cdot \omega_{1}}{\cos ^{2} \alpha_{i}}+\frac{F_{\tau} \cdot r_{b 1} \cdot \omega_{1}}{\cos ^{2} \alpha_{j}}+\frac{F_{\tau} \cdot r_{b 1} \cdot \omega_{1}}{\cos ^{2} \alpha_{k}}+\frac{F_{\tau} \cdot r_{b 1} \cdot \omega_{1}}{\cos ^{2} \alpha_{l}}} \\
& =\frac{4}{\frac{1}{\cos ^{2} \alpha_{i}}+\frac{1}{\cos ^{2} \alpha_{j}}+\frac{1}{\cos ^{2} \alpha_{k}}+\frac{1}{\cos ^{2} \alpha_{l}}} \\
& =\frac{4}{4+\operatorname{tg}^{2} \alpha_{i}+\operatorname{tg}^{2} \alpha_{j}+\operatorname{tg}^{2} \alpha_{k}+\operatorname{tg}^{2} \alpha_{l}}
\end{aligned}
$$

Equation 7 and 8 are auxiliary relations:

$$
\left\{\begin{array}{l}
K_{1} i=r_{b 1} \cdot \operatorname{tg} \alpha_{i} ; K_{1} j=r_{b 1} \cdot \operatorname{tg} \alpha_{j} ; K_{1} k=r_{b 1} \cdot \operatorname{tg} \alpha_{k} ; K_{1} l=r_{b 1} \cdot \operatorname{tg} \alpha_{l} \\
K_{1} j-K_{1} i=r_{b 1} \cdot\left(\operatorname{tg} \alpha_{j}-\operatorname{tg} \alpha_{i}\right) ; \\
K_{1} j-K_{1} i=r_{b 1} \cdot \frac{2 \cdot \pi}{z_{1}} \Rightarrow \operatorname{tg} \alpha_{j}=\operatorname{tg} \alpha_{i}+\frac{2 \cdot \pi}{z_{1}} \\
K_{1} k-K_{1} i=r_{b 1} \cdot\left(\operatorname{tg} \alpha_{k}-\operatorname{tg} \alpha_{i}\right) ; \\
K_{1} k-K_{1} i=r_{b 1} \cdot 2 \cdot \frac{2 \cdot \pi}{z_{1}} \Rightarrow \operatorname{tg} \alpha_{k}=\operatorname{tg} \alpha_{i}+2 \cdot \frac{2 \cdot \pi}{z_{1}} \\
K_{1} l-K_{1} i=r_{b 1} \cdot\left(\operatorname{tg} \alpha_{l}-\operatorname{tg} \alpha_{i}\right) ; \\
K_{1} l-K_{1} i=r_{b 1} \cdot 3 \cdot \frac{2 \cdot \pi}{z_{1}} \Rightarrow \operatorname{tg} \alpha_{l}=\operatorname{tg} \alpha_{i}+3 \cdot \frac{2 \cdot \pi}{z_{1}}
\end{array}\right.
$$




$$
\begin{aligned}
& \operatorname{tg} \alpha_{j}=\operatorname{tg} \alpha_{i} \pm \frac{2 \cdot \pi}{z_{1}} ; \operatorname{tg} \alpha_{k}=\operatorname{tg} \alpha_{i} \\
& \pm 2 \cdot \frac{2 \cdot \pi}{z_{1}} ; \operatorname{tg} \alpha_{l}=\operatorname{tg} \alpha_{i} \pm 3 \cdot \frac{2 \cdot \pi}{z_{1}}
\end{aligned}
$$

One keeps Equation 8, with a plus sign $(+)$ for the mechanism in the case in which the driving wheel 1 has teeth (regardless of whether it is matched external or internal), as well as with a sign (-) for the driving wheel 1 has internal teeth (drive wheel has a form of ring only for the inner drive). The relationship between the efficiency of the time (Equation 6) uses ancillary to the Equation 8 and take the form of Equation 9. In Equation 9, begin with Equation 6 in the case in which the four pairs are in contact at the

$$
\begin{aligned}
& \left\{\begin{array}{l}
\eta_{i}=\frac{4}{4+\operatorname{tg}^{2} \alpha_{i}+\operatorname{tg}^{2} \alpha_{j}+\operatorname{tg}^{2} \alpha_{k}+\operatorname{tg}^{2} \alpha_{l}} \\
=\frac{4}{4+\operatorname{tg}^{2} \alpha_{i}+\left(\operatorname{tg} \alpha_{i} \pm \frac{2 \pi}{z_{1}}\right)^{2}+\left(\operatorname{tg} \alpha_{i} \pm 2 \cdot \frac{2 \pi}{z_{1}}\right)^{2}+\left(\operatorname{tg} \alpha_{i} \pm 3 \cdot \frac{2 \pi}{z_{1}}\right)^{2}} \\
=\frac{4}{4+4 \cdot \operatorname{tg}^{2} \alpha_{i}+\frac{4 \pi^{2}}{z_{1}^{2}} \cdot\left(0^{2}+1^{2}+2^{2}+3^{2}\right) \pm 2 \cdot \operatorname{tg} \alpha_{i} \cdot \frac{2 \pi}{z_{1}} \cdot(0+1+2+3)} \\
=\frac{1+\operatorname{tg}^{2} \alpha_{i}+\frac{4 \pi^{2}}{E \cdot z_{1}^{2}} \cdot \sum_{i=1}^{E}(i-1)^{2} \pm 2 \cdot \operatorname{tg} \alpha_{i} \cdot \frac{2 \pi}{E \cdot z_{1}} \cdot \sum_{i=1}^{E}(i-1)}{1+\operatorname{tg}^{2} \alpha_{1}+\frac{4 \pi^{2}}{E \cdot z_{1}^{2}} \cdot \frac{E \cdot(E-1) \cdot(2 \cdot E-1)}{6} \pm \frac{4 \pi \cdot \operatorname{tg} \alpha_{1}}{E \cdot z_{1}} \cdot \frac{E \cdot(E-1)}{2}} \\
=\frac{1}{1+\operatorname{tg}^{2} \alpha_{1}+\frac{2 \pi^{2} \cdot(E-1) \cdot(2 E-1)}{3 \cdot z_{1}^{2}} \pm \frac{2 \pi \cdot \operatorname{tg} \alpha_{1} \cdot(E-1)}{z_{1}}} \\
\eta_{i}=\frac{1}{1+\operatorname{tg}^{2} \alpha_{1}+\frac{2 \pi^{2}}{3 \cdot z_{1}^{2}} \cdot\left(\varepsilon_{12}-1\right) \cdot\left(2 \cdot \varepsilon_{12}-1\right) \pm \frac{2 \pi \cdot \operatorname{tg} \alpha_{1}}{z_{1}} \cdot\left(\varepsilon_{12}-1\right)}
\end{array}\right. \\
& \eta_{m}=\frac{1}{1+\operatorname{tg}^{2} \alpha_{0}+\frac{2 \pi^{2}}{3 \cdot z_{1}^{2}} \cdot\left(\varepsilon_{12}-1\right) \cdot\left(2 \cdot \varepsilon_{12}-1\right) \pm \frac{2 \pi \cdot \operatorname{tg} \alpha_{0}}{z_{1}} \cdot\left(\varepsilon_{12}-1\right)} \\
& \varepsilon_{12}^{\text {a.e. }}=\frac{\sqrt{z_{1}^{2} \cdot \sin ^{2} \alpha_{0}+4 \cdot z_{1}+4}+\sqrt{z_{2}^{2} \cdot \sin ^{2} \alpha_{0}+4 \cdot z_{2}+4}-\left(z_{1}+z_{2}\right) \cdot \sin \alpha_{0}}{2 \cdot \pi \cdot \cos \alpha_{0}} \\
& \varepsilon_{12}^{a . i .}=\frac{\sqrt{z_{e}^{2} \cdot \sin ^{2} \alpha_{0}+4 \cdot z_{e}+4}-\sqrt{z_{i}^{2} \cdot \sin ^{2} \alpha_{0}-4 \cdot z_{i}+4}+\left(z_{i}-z_{e}\right) \cdot \sin \alpha_{0}}{2 \cdot \pi \cdot \cos \alpha_{0}}
\end{aligned}
$$


Table 1. Gear efficiency for different sets of gear transmission parameters

\section{The summarized results}

\begin{tabular}{|c|c|c|c|c|c|c|c|c|}
\hline$\underline{z_{1}}$ & $\alpha_{0}\left[^{\circ}\right]$ & $z_{2}$ & $\varepsilon_{12}^{a e}$ & $\eta_{12}^{a e}$ & $\eta_{21}^{a e}$ & $\varepsilon_{12}^{a i}$ & $\eta_{12}{ }^{a i}$ & $\eta_{21}^{a i}$ \\
\hline 42 & 20 & 126 & 1.79 & 0.844 & 0.871 & 1.92 & 0.838 & 0.895 \\
\hline 46 & 19 & 138 & 1.87 & 0.856 & 0.882 & 2.00 & 0.850 & 0.905 \\
\hline 52 & 18 & 156 & 1.96 & 0.869 & 0.893 & 2.09 & 0.864 & 0.915 \\
\hline 58 & 17 & 174 & 2.06 & 0.880 & 0.904 & 2.20 & 0.876 & 0.925 \\
\hline 65 & 16 & 195 & 2.17 & 0.892 & 0.914 & 2.32 & 0.887 & 0.933 \\
\hline 74 & 15 & 222 & 2.30 & 0.903 & 0.923 & 2.46 & 0.899 & 0.942 \\
\hline 85 & 14 & 255 & 2.44 & 0.914 & 0.933 & 2.62 & 0.910 & 0.949 \\
\hline 98 & 13 & 294 & 2.62 & 0.924 & 0.941 & 2.81 & 0.920 & 0.956 \\
\hline 115 & 12 & 345 & 2.82 & 0.934 & 0.949 & 3.02 & 0.931 & 0.963 \\
\hline 137 & 11 & 411 & 3.06 & 0.943 & 0.957 & 3.28 & 0.941 & 0.969 \\
\hline 165 & 10 & 495 & 3.35 & 0.952 & 0.964 & 3.59 & 0.950 & 0.974 \\
\hline 204 & 9 & 510 & 3.68 & 0.960 & 0.970 & 4.02 & 0.958 & 0.980 \\
\hline 257 & 8 & 514 & 4.09 & 0.968 & 0.975 & 4.57 & 0.966 & 0.985 \\
\hline 336 & 7 & 672 & 4.66 & 0.975 & 0.980 & 5.21 & 0.973 & 0.989 \\
\hline 457 & 6 & 914 & 5.42 & 0.981 & 0.985 & 6.06 & 0.980 & 0.992 \\
\hline 657 & 5 & 1314 & 6.49 & 0.986 & 0.989 & 7.26 & 0.986 & 0.994 \\
\hline
\end{tabular}

The results of the calculations carried out for various transmission parameters are presented on the short in Table 1.

\section{Efficiency of Helical Gears as a Function of Contact Ratio}

In the would there are wheels of the helical gears, which are used very often. For helical gears, the calculations show a decrease in the efficiency of the with the tilt angle on the rise of the teeth $(\beta)$. For given angle which does not exceed $25^{\circ}$, the efficiency of fishing gear is good enough. However, when the tilt angle is greater than $25^{\circ}$, speeds will suffer a significant decrease in the yield (Pelecudi et al., 1985; Petrescu and Petrescu, 2002; 2003; Petrescu et al., 2007; Petrescu, 2013). Calculation relationships may be given in Equation 13-15:

$$
\begin{aligned}
& \eta_{m}=\frac{z_{1}^{2} \cdot \cos ^{2} \beta}{z_{1}^{2} \cdot\left(\operatorname{tg}^{2} \alpha_{0}+\cos ^{2} \beta\right)+\frac{2}{3} \pi^{2} \cdot \cos ^{4} \beta \cdot(\varepsilon-1) \cdot(2 \varepsilon-1)} \\
& \pm 2 \pi \cdot \operatorname{tg} \alpha_{0} \cdot z_{1} \cdot \cos ^{2} \beta \cdot(\varepsilon-1)
\end{aligned}
$$

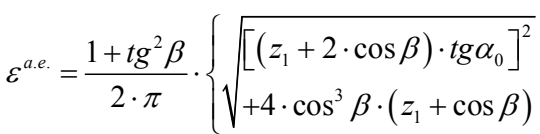

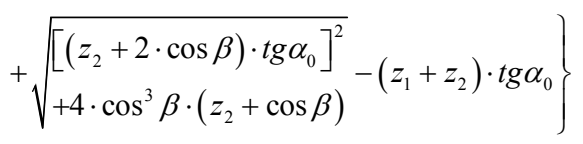

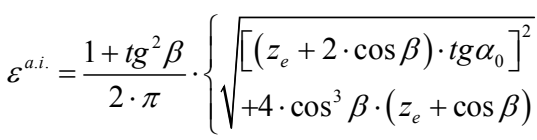

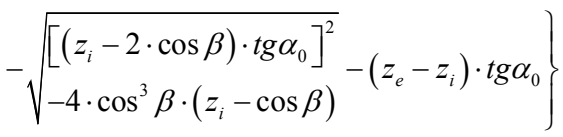

\section{Validation}

All relations submitted have been validated through the use of the software package "inventor" and a very good compliance has been confirmed. More examples have been calculated for both mesh in internal and foreign affairs as well. The pairs of corresponding gearbox have pulled out automatically by the "Inventor". Figure 16 and 17 describe the pairs of gearbox, together with the main parameters of the tools to be taken into consideration for engagement external and internal, (Pelecudi et al., 1985; Petrescu and Petrescu, 2002; 2003; Petrescu et al., 2007; Petrescu, 2013). For the angle $\alpha_{0}$ between $10^{\circ}$ and $20^{\circ}$, line of contact is perfect. For more than $25^{\circ}$, the software confirms that such a design is no longer sure and for $\alpha_{0}$ with values less than $10^{\circ}$, the software does not have the necessary particulars for operational, since it relies on the experimental values, which not longer exists for such low values of $\alpha_{0}$ angle.

\section{Discussion}

The gears are today the most widespread and most frequently used mechanical transmissions, all over the world.

They must be the factory on an industrial scale, everywhere and have a variety of uses, be extremely important for both heavy machines of industrial buildings, as well as for domestic appliances, electronics, etc. meet the size of the normal excessive, big or even huge (used from ships, heavy machines or in energy), but also for watches tools, or for devices of sizes micro.

The work of his wishes to make an overview of the toolbar and then an introduction to the study of their general and a study customized for gears with fixed. The methods listed for the gears with fixed rate, can then be customized and used and the planetary gears (drive shaft with the shaft). 
Relly Victoria V. Petrescu et al. / American Journal of Engineering and Applied Sciences 2017, 10 (2): 473.483
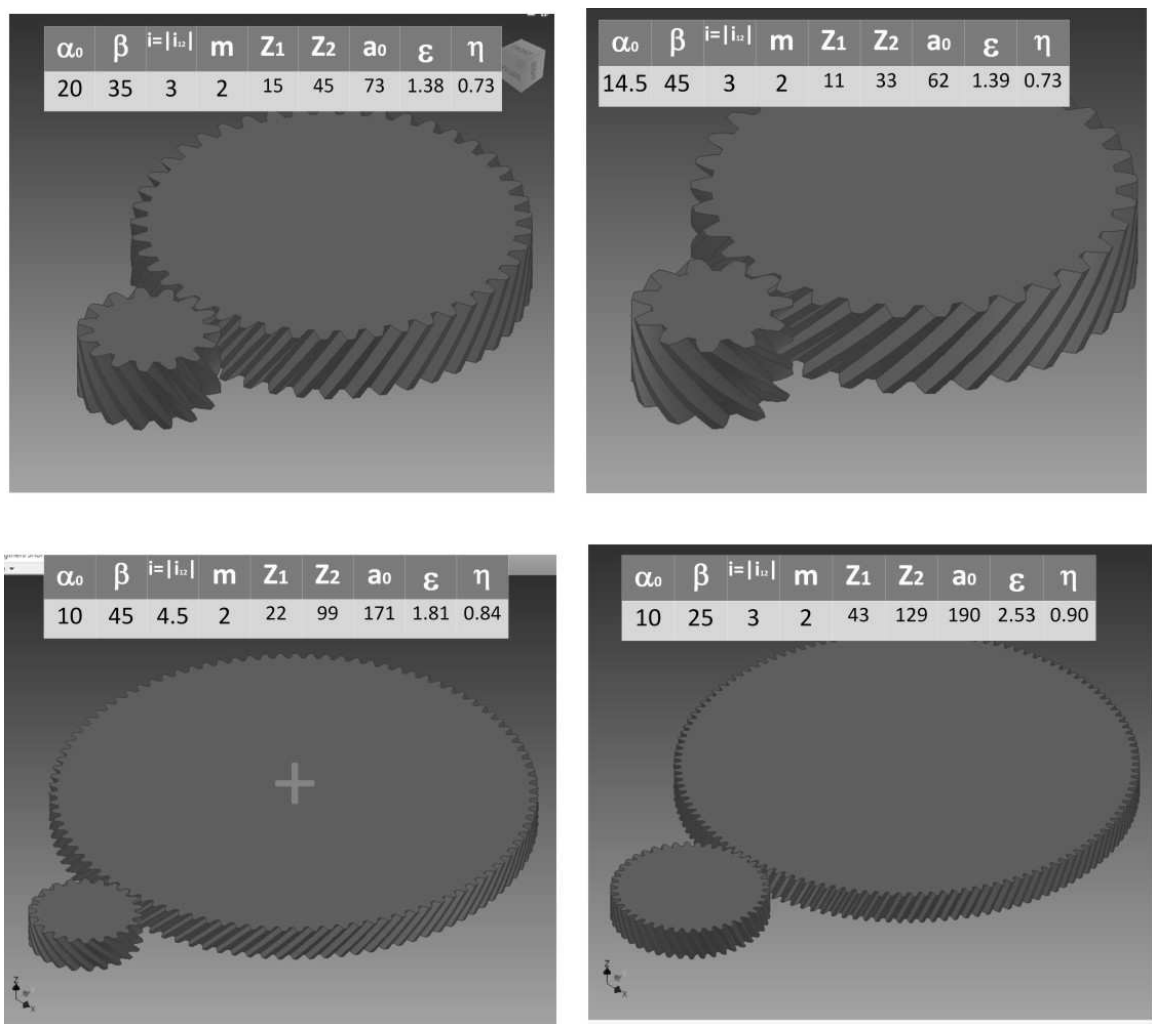

Fig. 16. Validated examples of external gearing
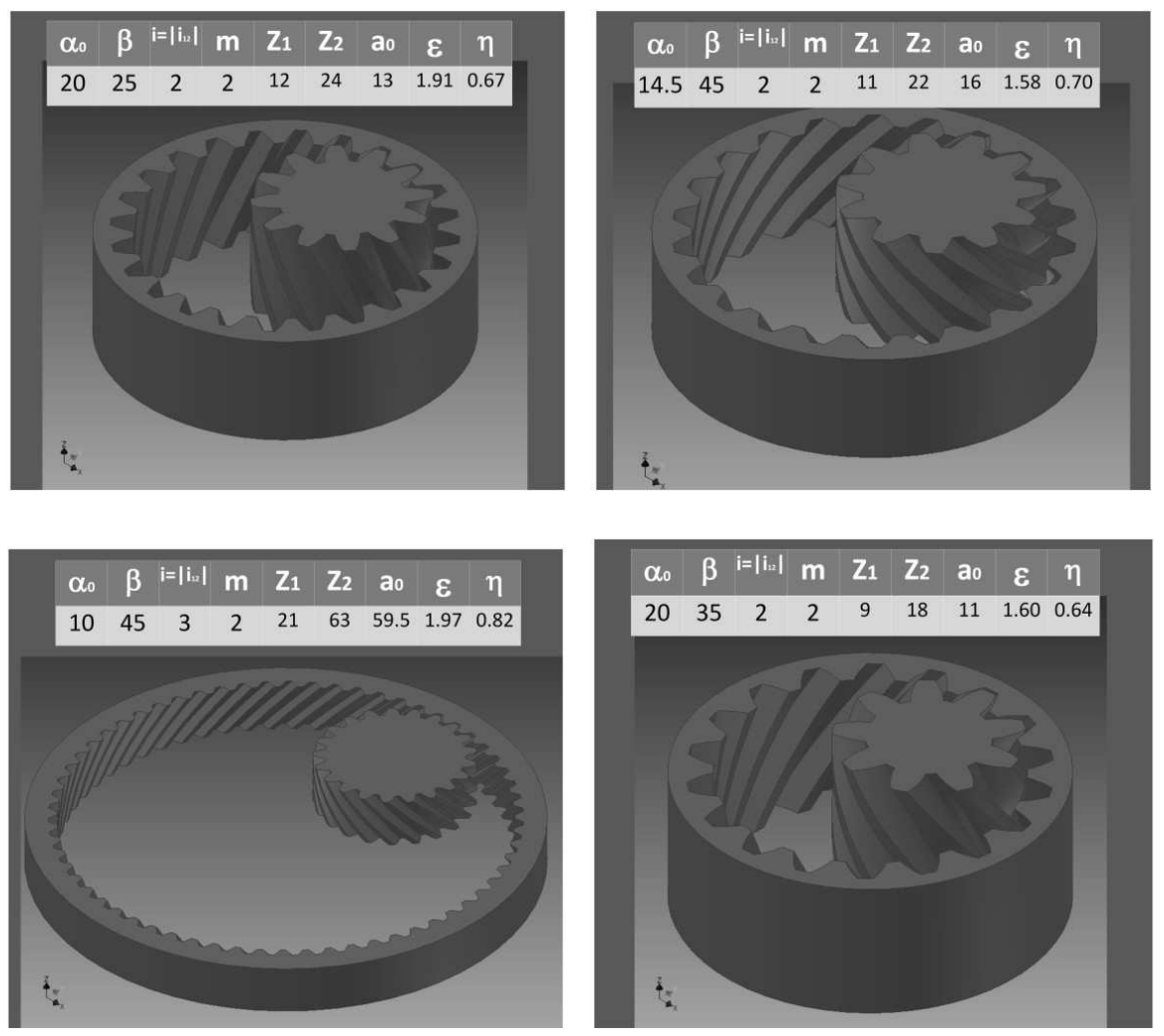

Fig. 17. Validated examples of internal gearing 
The work of the original components, very much, such as the front and the geometry, Forces, automatic gearbox, powers, outputs (Tools), which form part of the actual dynamics of the mechanisms and also the most important criterion in terms of performance of a mechanism.

Gears, broke today in all the fields of activity.

They have the advantage of working with very high efficiency.

In addition, gears may transmit the heavy loads. Irrespective of their size, the tools must be synthesized taking into account the conditions carefully.

The work of the front is trying to present the main conditions which must be met in order to correct the synthesis of a tool.

In accordance with the existing standards, a drive is defined as a basic mechanism which consists of two elements gear (wheels, sectors or the toothed bar), being in rotation movement/translation absolute or relative, in which one of the components other acts by the action of the teeth which are in contact in succession and continuously.

The gears or mechanisms with gears, are practically couplers upper (in general class a fourthC4), which are intended to transmit and or to transform the movement by reducing the speed of rotation (with increasing the moment), or by the increase of the angular speed (with a decrease in the torque) from the entrance toward the exit, by maintaining the power approximately constant (with losses very small, mechanical and friction, yields due to the large and extra large to which non-gears are).

\section{Conclusion}

The paper presents an original method for the determination of the yield of the gearbox, gears forces, gearbox and power.

It analyzes the influence of certain parameters which affects the efficiency of the gearbox.

Also an original method for the determination of the yield of the driveshafts oriented on the basis of the ratio of contact is presented the brief.

The relations submitted, can be dynamic synthesis of the driveshafts oriented, in order to enhance the effectiveness of the mechanisms of mesh.

The best efficiency is achieved with the inner drive when the drive wheel 1 is a ring.

Minimum efficiency will be obtained when the drive wheel 1 of the internal gearing has teeth.

For external drives, best efficiency is achieved when the wheel is the drive wheel.

With the decrease in the angle of the normal $\alpha_{0}$, pin increases the report and increase the efficiency and.

The effectiveness of the measure also increases when the number of teeth of the drive wheel $1\left(z_{1}\right)$ increases.

\section{Acknowledgement}

The base of this paper, presented by the corresponding author (first time) in 2002, was acknowledged and appreciated by Royal British House, by her scientific adviser, courtesy of the British Embassy in Romania in spring-summer of 2002, with wishes of success for the corresponding author and indeed, the work has enjoyed great success.

I wish in this way, to address Her Majesty Queen Elizabeth II, wishes for a long life with health, many achievements and joys. God save the Queen !

\section{Funding Information}

Research contract: Contract number 36-5-4D/1986 from 24IV1985, beneficiary CNST RO (Romanian National Center for Science and Technology) Improving dynamic mechanisms.

All these matters are copyrighted! Copyrights: 394-qodGnhhtej from 17-02-2010 13:42:18; 396qkzAdFoDBc from 17-02-2010 17:43:22; 951cnBGhgsHGr from 26-01-2011 16:29:02; 1375tnzjHFAqGF from 02-09-2011 15:19:23.

The cutting action depends on the process.

In the case of plastic parts, the individual parts are generally cut, but for series production they are generally molded.

The modules are standardized. There are the main values, the secondary values and the exceptional values (in parentheses and in italics).

\section{Author's Contributions}

All the authors contributed equally to prepare, develop and carry out this manuscript.

\section{Ethics}

This article is original and contains unpublished material. Authors declare that are not ethical issues and no conflict of interest that may arise after the publication of this manuscript.

\section{References}

Lei, X.M., Y.Z. Ge, Y.C. Zhang and P. Liu, 2011. Design and analysis for high-speed gear coupling. Applied Mechan. Mater., 86: 658-661. DOI: 10.4028/www.scientific.net/AMM.86.658

Lin, C., Y.J. Hou, Q.L. Zeng, H. Gong and L. Nie et al., 2011. The design and experiment of oval bevel gear. Applied Mechan. Mater., 86: 297-300.

DOI: 10.4028/www.scientific.net/AMM.86.297

Maros, D., 1958. Cinematica roţilor dinţate. Editura Tehnică, Bucureşti. 
Matos, L. and B. Marinho, 2011. A comparison of the delay spread obtained with different power delay profiles denoising techniques. Engevista, 13: 129-133.

Mirsayar, M.M., V.A. Joneidi, R.V.V. Petrescu, F.I.T. Petrescu and F. Berto, 2017. Extended MTSN criterion for fracture analysis of soda lime glass. Eng. Fracture Mechan., 178: 50-59.

DOI: 10.1016/j.engfracmech.2017.04.018

Nogueira, O.C. and M.V. Real, 2011. Estudo comparativo de motores diesel maritimos atraves da analise de lubrificantes usados e engehharia de confiabilidade. Engevista, 13: 244-254. 3

Oliveira, M.M.P. and F.R. Lima, 2003. Analogias entre o desenho instrumental e o dedenho computacional. Engevista.

Pelecudi, C.H.R.., D. Maros, V. Merticaru, N. Pandrea and I. Simionescu, 1985. Mecanisme. Editura Didactică şi Pedagogică, Bucureşti.
Petrescu, V. and I. Petrescu, 2002. Randamentul cuplei superioare de la angrenajele cu roţi dinţate cu axe fixe. Proceedings of the 7th National Symposium PRASIC, (PRASIC' 02), Braşov, pp: 333-338.

Petrescu, R. and F. Petrescu, 2003. The gear synthesis with the best efficiency. Proceedings of ESFA, (ESFA' 03), Bucharest, pp: 63-70.

Petrescu, R.V., F.I. Petrescu and N. Popescu, 2007. Determining gear efficiency. Gear Solutions.

Petrescu, F.I., 2012. Teoria mecanismelor-Curs si aplicatii (editia a doua). 1st Edn., Create Space Publisher, USA, pp: 284.

Rey, G.G., 2013. Influencia de la lubricacion en la eficiencia de engranajes de tornillo sinfin. Ingineria Mecanica, 16: 13-21.

Stoica, I.A., 1977. Interferenţa roţilor dinţate. Editura DACIA, Cluj-Napoca. 